\title{
Diffusion of Innovation in Sustainable Development Projects: A Proposed Integrative Model
}

\author{
Afaf Hassan \\ Environmental and Public Health Department, Abu Dhabi University \\ PO Box 5911, Abu Dhabi, United Arab Emirates \\ Tel: 971-2501-5427Ｅ-mail: afaf.hassan@adu.ac.ae
}

Received: January 6, 2022 Accepted: February 11, 2022 Published: February 18, 2022

doi:10.5296/emsd.v11i2.19553 URL: https://doi.org/10.5296/emsd.v11i2.19553

\begin{abstract}
To support an effective diffusion of innovations (DOI) in sustainable development (SD) projects, this paper presents a research-based integrative model to illustrate the factors leading the process of diffusion of innovation to succeed or fail in sustainable development projects. The proposed integrative model is based on diffusion of innovation principles founded in the research of Everett Rodgers that emphasizes the process of an effective innovation diffusion. Special emphasis is placed on determining not only the success factors for adequate innovation diffusion, but also on enabling a successful adoption to take place. Key finding obtained from the proposed integrative model is that there are three main stages for adopting DOI in SD projects that are creation of innovative ideas in SD projects, DOI ideas in SD projects, and adoption of innovative ideas in sustainable development projects. Each one of these stages leads to two possibilities that are the success or failure of that stage, depending of the fulfillment of the suggested factors for each option. In brief, the suggested integrated model proposes that the DOI in SD projects will succeed if the three core stages meet the success factors.
\end{abstract}

Keywords: Diffusion of innovation, Sustainable development projects

\section{Introduction}

Innovation has been considered as a creative idea that project professionals adopts to gain more benefits in SD projects, considering any uncertainties or risks that may occur (Ling et al., 2007). The new ideas in SD projects can stand for a new material, design, technology or method that provides favorable outcomes (Ling et al., 2007). Through time, this has been generalized and innovation has been redefined several times. Other scholars have described innovation as an effective application of a new idea, object, strategy, services, or process in 
projects, but they do not, necessary, have to be new to everyone (Dingfelder \& Mandell, 2011; Samson \& Gloet, 2014). Yet, innovation's definition could be expanded to cover "the ability to transfer knowledge from the point of origin to the point of highest need across the complete whole product life cycle and diffusion of innovation curve from ideation to market saturation" (Schwabe et al., 2021, P. 196).

However, the diffusion of innovation is a critical issue; the success of innovation mostly depends on the long-term completion accuracy level and the speed of diffusion (Szymczyk \& Kaminski, 2014). Diffusion of innovation in SD projects is an important issue that entails many success and failure factors (Adams, 2016; Alyoubi \& Yamin, 2021; Banytė \& Salickaite, 2008; Rogers 2008; Samson \& Gloet, 2014; Szymczyk \& Kaminski, 2014). Here, it is important to point out some factors that are linked to DOI in sustainable development projects. Effective DOI enhances economic growth (Ende et al., 2015; Ion \& Cristina, 2014; Samson \& Gloet, 2014), encourages positive competition (Ende et al., 2015; Lim et al., 2010), improve markets, and make them more attractive and stable (Bozkurt \& Kalkan, 2014; Szymczyk \& Kaminski, 2014), introduces new technologies that can accelerate the performed activities (Middleton, 2010), enhances committed to policies associated with innovation management (Samson \& Gloet, 2014; Shieh, 2011), offers better quality (Samson \& Gloet, 2014; Szymczyk \& Kaminski, 2014), and offers innovation culture that helps the SD project professionals move from traditional ways of performing projects to new reliable methods (Samson \& Gloet, 2014; Shieh, 2011). On the other side, there are many challenges for the DOI in SD projects that project professionals should overcome. For example, additional costs of innovation, unavailability of required material, inexperienced project team members, and resistance to change are critical challenges to achieving innovation (Gambatese \& Hallowell, 2011; Middleton, 2010). The profits are hard to be expected as most of the activities are technologies that are new to project professionals (Lim et al., 2010). An adequate design and implementation plan are essential to reduce any potential of innovation failure in SD projects (Murphy et al., 2015). The low availability of innovation resources could have negative influences on innovation, in SD projects' settings (Chatenier et al., 2010). This is study is significant, as it proposes an integrative model that illustrates the success and failure factors throughout the different stages of the DOI process in SD projects.

Besides, the DOI theory has been widely used in sustainable development projects' literature; in contrast, the application of this theory in traditional projects' contexts is minimal (Okour et al., 2021). It provides a better understanding of the success and failure factors, as it demonstrates the consequences that could happen if individuals decide to adopt or reject innovation (Okour et al., 2021). Hence, this study has used DOI theory to bridge the gap between sustainable development and traditional projects' literature. At the same time, this research considers the absence of knowledge or information quality in about the success or failure factors of diffusion of innovation in sustainable development projects. In this respect, this paper aims to fill this conceptual gap by assessing the influence of DOI success and failure factors on the implementation of sustainable development projects, in an integrated model. 


\section{Macrothink}

\section{Method}

This study adopted the systematic literature review approach that was introduced by Page et al. (2021). Particularly, the conducted review was based on peer-reviewed literature published in international scientific journals. The key terms, such as diffusion of innovation and sustainable development project, were used to find the relevant articles from Abu Dhabi University (ADU) Online Library and Google Scholar. The searches in both the ADU library and Google Scholar database yielded a total of fifty-five peer-reviewed articles. The author found these articles to be relevant, rich in content, and supportive for the various arguments of this study. Thus, the author has followed the steps illustrated in Figure 1 to conduct the systematic review efficiently (Page et al., 2021).

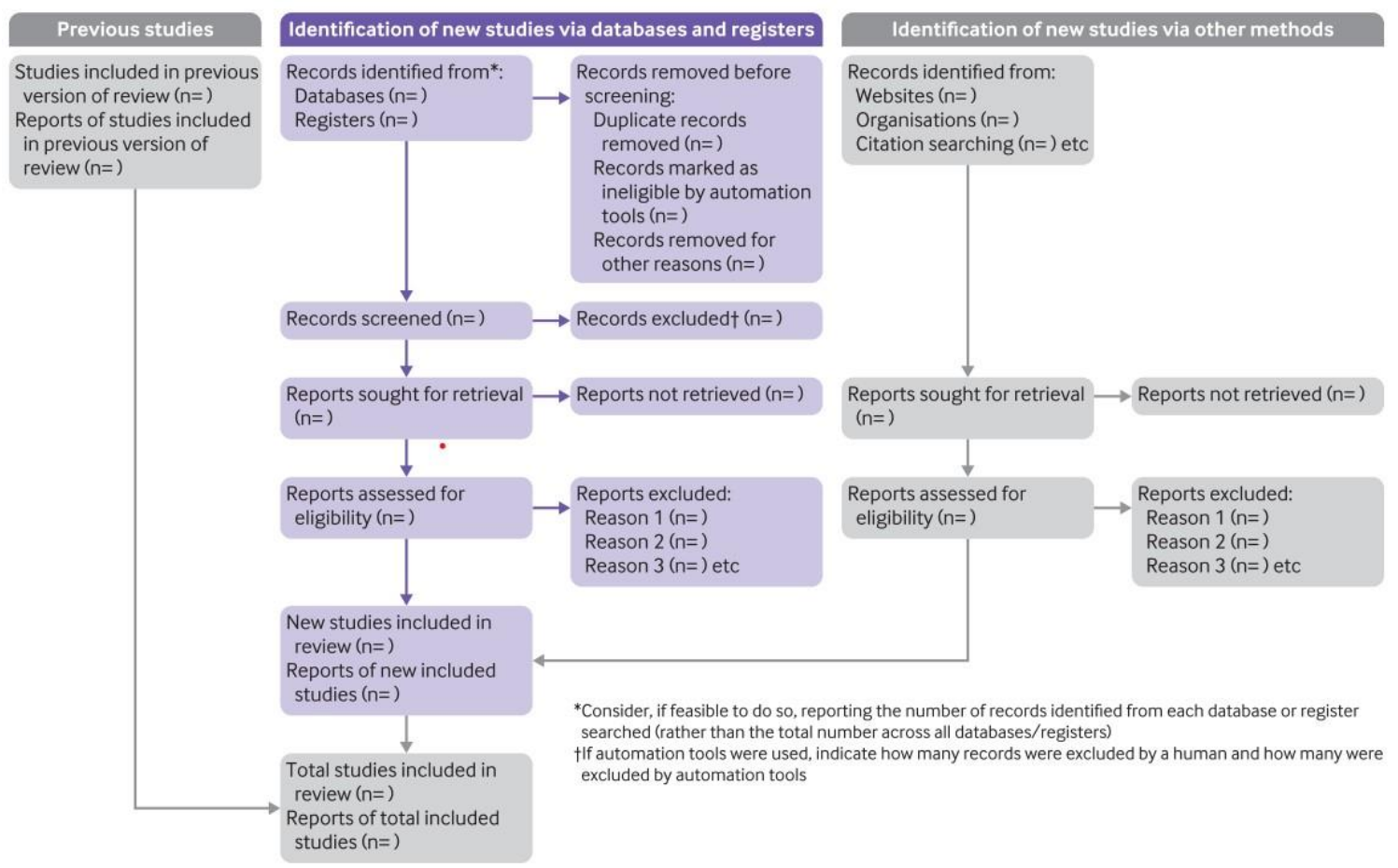

Figure 1. PRISMA 2020 flow diagram for systematic reviews (Page et al., 2021)

In detail, each one of the collected previous studies was screened by the author. To complete the analysis, the inclusion criteria were focused on articles discussing the diffusion of innovation in sustainable development projects. Hence, the author read the abstracts of each article and, if the paper is related to the topic of the research, the author continued reading the method and conclusion sections to make sure that the article fulfilled the inclusion criteria. At the same time, irrelevant articles were excluded and removed. In addition, the author has adopted the PRISMA 2020 Checklist for systematic review established by Aczel et al. (2020). The checklist covers the criteria summarized in Table 1 . 
Table 1. PRISMA 2020 Checklist (available at https:// prisma.shinyapps.io/checklist/)

\begin{tabular}{|c|c|}
\hline 1 & Title (relevant) \\
\hline 2 & $\begin{array}{l}\text { Abstract (PRISMA } 2020 \text { Abstract Checklist available at } \\
\text { https://prisma.shinyapps.io/checklist/) }\end{array}$ \\
\hline 3 & Introduction (rational and objectives) \\
\hline 4 & $\begin{array}{l}\text { Methods (Eligibility criteria, information sources, search strategy, selection process, data } \\
\text { collection process, data items, study risk of bias assessment, effect measures, synthesis } \\
\text { methods, reporting bias assessment, and certainty assessment) }\end{array}$ \\
\hline 5 & $\begin{array}{l}\text { Results (study selection, study characteristics, risk of bias in studies, results of individual } \\
\text { studies, results of syntheses, reporting biases, and certainty of evidence) }\end{array}$ \\
\hline 6 & Discussion (general interpretation, limitations, and implications) \\
\hline 7 & $\begin{array}{l}\text { Other information (Registration and protocol, support, competing interests, and } \\
\text { availability of data, code and other materials) }\end{array}$ \\
\hline
\end{tabular}

Mainly, the author identified the fifty-five related articles through manual search using ADU Library and Google Scholar. Some articles were eliminated after the content verification process demonstrated in Table 1, as they were found to be irrelevant. The remaining articles were examined and evaluated for eligibility. This reduced the number of studies from fifty-five to forty-seven journal articles. These forty-seven peer-reviewed articles were used to develop the proposed integrative model of this study. The model combined the knowledge, arguments, and findings of these articles to establish a new integrative model that covers three main stages that are the creation of innovative ideas in sustainable development projects; diffusion of innovative ideas in sustainable development projects; and adoption of innovative ideas in sustainable development projects, respectively (Adams, 2016; Banytė \& Salickaite, 2008; Rogers 2003). Eventually, the valuable information attained from these studies was used to satisfy the main purpose of this research, which is proposing a robust integrative model that explains the success and failure factors of the diffusion of innovation in sustainable development projects.

\section{Literature Review}

\subsection{Diffusion of Innovation}

Diffusion of innovation theory was initially presented by Rogers in 1962 and included four elements that are communication, time, social system, and innovation ((Alyoubi \& Yamin, 2021; Rogers, 2003). DOI was initially developed by Rogers (1962) and has since been used in several fields such as education, business, anthropology, sociology, marketing, and general economics (Rogers, 2003; Okour et al., 2021). Since that time, numerous studies have used Rogers' DOI theory to explain issues related to technological innovations (Alyoubi \& Yamin, 2021; Evanschitzky et al., 2012; Okour et al., 2021; Szymczyk \& Kaminski, 2014). However, considering the dynamic global changes, Rogers revised the DOI theory in 2003 and revealed five phases that are persuasion, implementation, decision, confirmation, and knowledge (Alyoubi \& Yamin, 2021; Rogers, 2003). In the beginning, DOI included two factors that are 
compatibility and innovativeness. Prior researches had agreed about the importance of both compatibility and innovativeness in adopting innovation (Rogers, 2003; Lee et al., 2011). Rogers has developed the DOI theory to cover the main characteristics for innovation adoption and application that are compatibility, relative advantage, observability, complexity, and trialability are (Okour et al., 2021; Roger, 2003). Later, other constructs were considered such as trust in technology, employee self-efficacy, the gap in capabilities, service quality, and financial capabilities (Alyoubi \& Yamin, 2021). This was followed by the introduction of the diffusion of innovation curve (Alyoubi \& Yamin, 2021; Schwabe et al., 2021). It illustrated innovation stages from ideation to market saturation (Alyoubi \& Yamin, 2021; Schwabe et al., 2021). The innovation curve involved roles described as "innovators", "early adopters", "early majority", "late majority" and "laggards" (Schwabe et al., 2021). In particular, the inventor enjoys experimentation and coordinates with inventors; innovators are open to change; early adopters act as influencers sharing success stories; early majority adopters are followers who are open to change but require support from earlier adopter users; late majority adopters are not interested in change and often adopt innovations, if necessary; and Laggard adopters need to understand the benefits to adopt the change (Schwabe et al., 2021). Furthermore, the application of the DOI theory could lead to some social changes. In clarification, social change could take place when new ideas are created, diffused among individuals, and accepted or rejected (Schleien \& Miller, 2010). In this concern, Schleien and Miller (2010) have stated that the DOI theory relies on main aspects such as the speed of innovation adoption, individuals involved, and communication channels used.

Diffusion of innovation is defined as "the process by which an innovation (idea) is communicated through certain channels over time amongst the members of a social system" (Rogers, 2003, p. 5). Scholars have categorized the DOI process into various stages (Evanschitzky et al., 2012; Larsen, 2011; Szymczyk \& Kaminski, 2014). For example, Larsen (2011) has suggested that the innovation diffusion process could be categorized into three phases that are awareness, influence, and social networks. Evanschitzky et al. (2012) has mentioned five main categories for the success of DOI that are marketplace, strategy, process, product, and organizational characteristics. While, Szymczyk and Kaminski (2014) have stated that there are three classes of attributes that drive the dynamic of DOI, which are innovations' features, innovators' characteristics, and environmental setting.

The uncertainties associated with the diffusion of innovation give rise to concern in sustainable development projects (Schwabe et al., 2021). High uncertainty commonly exists, because the required changes are new, including highly regulated design and engineering solutions (Schwabe et al., 2021). This has encouraged researchers to look at factors that could increase or decrease the level of uncertainties, which could in turn lead to the success or failure of innovation (Schwabe et al., 2021). For example, Lee et al. (2011) have argued that the diffusion of innovation theory highlights five main characteristics that are compatibility, complexity, relative advantage, observability, and trialability. In specific, compatibility is the degree to which innovation is being consistent with the values of end-users, past experiences, and demands. Complexity is associated with the level of difficulty that the end confronts to accept innovations. Relative advantage is the degree to which innovation is being better than 
the original idea. Observability is the degree to which the outcomes of innovation are visible. Trialability is the degree to which innovation is being verified on a limited basis (Lee et al., 2011).

Nevertheless, "Diffusion of Innovation theory provides prescribed stages for an innovation to traverse, to obtain field adoption" (Gayadeen \& Phillips, 2014, P.228). In the context of knowledge utilization and collaboration among project team members, (Okour et al., 2021) have pointed out that DOI theoretical models could provide a comprehensive demonstration and explanation about how knowledge could be created and shared amongst individuals within projects in comparison with other theoretical models. In support, Okour et al. (2021) emphasized that the DOI theory is one of the most widely examined theories over the past two decades. At the same time, scholars have agreed that individuals would engage in activities that lead to the adoption or rejection of an innovation (Alyoubi \& Yamin, 2021; Rogers 2003).

\subsection{Sustainable Development Projects}

Sustainable development principles are widely demonstrated using the "triple bottom line" theory. The TBL mainly considers the economic, social, and environmental dimensions of a project (Adams et al., 2016; Brem \& Puente-Díaz, 2020; Li et al., 2021; Maier et al., 2020) The significance of these three pillars has led to ongoing argument over what constitutes SD of projects, resulting in various interpretations ( $\mathrm{Li}$ et al., 2021). In clarification, many scholars proposed that the importance of sustainable development projects remains within absolute environmental limits when meeting economic and social needs (Brem \& Puente-Díaz, 2020; Li et al., 2021; Maier et al., 2020). Li et al. (2021) have mentioned that the three-pillar model of sustainable development is considered as a process of dynamic balance, where the three dimensions ignore the interconnection among social, environmental, and economic perspectives. Thus, recent studies have highlighted the importance of synergy between the SD dimensions (Cano \& Londoño-Pineda, 2020; Li et al., 2021; Maier et al., 2020). Later, the dependencies between the environmental, economic, and social dimensions of sustainable development have been identified (Adams et al., 2016; Brem \& Puente-Díaz, 2020; Li et al., 2021; Maier et al., 2020). Besides, it had been added that and SD projects should involve stakeholder cooperation to balance the three dimensions of sustainability (Adams et al., 2016; Brem \& Puente-Díaz, 2020; Li et al., 2021; Maier et al., 2020). Nevertheless, some recent studies have suggested other dimensions that go beyond the three pillars of social, ecological, and economic sustainability (Li et al., 2021; Maier et al., 2020). For example, researchers have mentioned that aspects, such as politics, management, balance, or other intangibles, could complement the three SD pillars (Brem \& Puente-Díaz, 2020; Li et al., 2021; Maier et al., 2020).

Sustainable development definitions could vary, but in common, they all involve environmental protection, social inclusion, and economic growth (Sachs, 2012). Sustainable development refers to "people-centered development and ending poverty and distributional equity as key objectives; structural transformation of national economies and reforms in global economic governance to create an enabling environment for development" 
(Fukuda-Parr \& Muchhala, 2020, p.104706). Accordingly, sustainable development projects are projects that incorporate enhancements in three pillars of sustainability that are economic, social, and environmental issues (Ciegis et al., 2011). Another way to define SD projects is that they are projects that encourage existing generations to meet their needs without compromising the capacity of future generations to meet their needs as well (Remington-Doucette \& Musgrove, 2015).

Sustainable development projects' framework covers a wide variety of economic, environmental, and social issues, including climate change, biodiversity, energy, gender, security, equality, peace, healthcare, education, economic growth, food supply, and sustainable production and consumption (Secundo et al., 2020). In addition, SD projects aim to find effective solutions for complex challenges such as ecosystem resilience, energy, pollution, climate change, food security, migration, and many other issues (Secundo et al., 2020). Wiek et al. (2011) have agreed that several SD projects are designed to respond to current and anticipated problems such as climate change, pandemics, desertification, poverty, climate change, a war that is, in general, featuring high degrees of complexity, damage potential, and urgency.

\subsection{Diffusion of Innovation in Sustainable Development Projects}

Diffusion of innovation in SD projects generates a need for connection between technological innovations and social innovations (Choi, 2020; Payán-Sánchez et al., 2021). The DOI process would help to address challenges that could exist in SD projects such as additional costs of innovation, unavailability of required material, inexperienced project team members, and resistance to change are critical challenges to achieving innovation (Gambatese \& Hallowell, 2011; Middleton, 2010; Payán-Sánchez et al., 2021).

Recently, DOI in SD projects has become crucial due to the global concern about the impact that innovation could have on the environment, resources, and society (Payán-Sánchez et al., 2021; Yun \& Liu, 2019). In general, sustainable development brings inherent degrees of complexity, uncertainty, and huge challenges (Bogers et al., 2020; Payán-Sánchez et al., 2021). However, the focus and mechanisms of innovation diffusion in SD projects have shifted to society (Payán-Sánchez et al., 2021). Hence, to face sustainable development problems, many scholars have called for a collaborative effort to ensure successful adoption and implementation of innovation in SD projects through dynamic, flexible, and open platforms (Bogers et al., 2020; Payán-Sánchez et al., 2021; Yun \& Liu, 2019). Research has shown that diffusing innovative processes efficiently in SD projects contributes to the achievement of competitive advantages (Lim et al., 2010; Payán-Sánchez et al., 2021). Consequently, one of the greatest benefits of innovation diffusion correctly is the positive impact on environmental, social, and economic sustainable development (Ciegis et al., 2011; Payán-Sánchez et al., 2021; Sachs, 2012). Thus, That DOI may play a relevant role towards an efficient, tactical, and sustainable management (Samson \& Gloet, 2014; Shieh, 2011).

Nevertheless, DOI in SD projects is associated with several factors that can drive the success or failure of innovation. For example, competition as the slow reaction of some other competitors to innovation strategies could result in creating a competitive advantage (Lim et 
al., 2010; Payán-Sánchez et al., 2021). An attractive market is the most influential factor on the speed of innovation diffusion (Szymczyk \& Kaminski, 2014), while an unattractiveness or instability market can negatively influence the diffusion of innovation (Bozkurt \& Kalkan, 2014). The increasing number of technology adopters, which indicates that professionals overcame the issue of resistance to change, and (now) they prefer to use technologies (Middleton, 2010). Innovation cost, since most project owners or shareholders, are becoming more concerned than ever about cutting costs (Middleton, 2010). In addition, a successful DOI can provide concerned professionals in SD projects with the ability to capture a substantial level of market share or create a new market opportunity that enables them to gain profits (Lim, Schultmann \& Ofori, 2010). An adequate innovation adoption time enhances the opportunity to train employees to effectively use new technologies (Christie \& Jurado, 2009). At the same time, it provides enough duration to introduce innovation to management, and SD project team members (Christie \& Jurado, 2009). A well-defined innovative conception makes a major difference to how involved individuals learn, how fast they could master skills, and how much they could enjoy learning (Bhardwaj, Singh \& Kharayat, 2011). The quality of innovation that various competitors offer is a significant parameter for the success of innovation (Szymczyk \& Kaminski, 2014). Innovation culture helps the SD project professionals move from traditional ways of performing projects to new reliable methods, as an innovative culture enhances the manners of thinking, execution process, and implementation of innovation (Shieh, 2011).

\section{Theoretical Framework}

The theoretical framework of this study was developed considering the output of several authors, who contributed their knowledge in relevant studies that formed the basis for the proposed integrative model, as demonstrated in Table 2. 


\section{Macrothink

Table 2. Theoretical Framework

\begin{tabular}{|l|l|l|}
\hline No. & $\begin{array}{l}\text { Stages of the diffusion of } \\
\text { innovation in sustainable } \\
\text { development projects }\end{array}$ & Authors \\
\hline 1 & $\begin{array}{l}\text { Creation of innovative ideas } \\
\text { in sustainable development } \\
\text { projects has success and } \\
\text { failure factors. }\end{array}$ & $\begin{array}{l}\text { Alyoubi \& Yamin, 2021; Banyte \& Salickaite, 2008; } \\
\text { Chatenier et al., 2010; Gambatese \& Hallowell, 2011; } \\
\text { Gayadeen \& Phillips, 2014; Ling et al., 2007; Murphy } \\
\text { et al., 2015; Okour et al., 2021; Ozorhon, 2013; Rogers } \\
\text { 2008; Samson \& Gloet, 2014; Szymczyk \& Kaminski, } \\
\text { 2014. }\end{array}$ \\
\hline 2 & $\begin{array}{l}\text { Diffusion of innovative } \\
\text { ideas in sustainable } \\
\text { development projects has } \\
\text { success and failure factors. }\end{array}$ & $\begin{array}{l}\text { Adams, 2016; Banyte \& Salickaite, 2008; Bozkurt \& } \\
\text { Kalkan, 2014; Brem \& Puente-Díaz, 2020; Chatenier et } \\
\text { al., 2010; Cano \& Londoño-Pineda, 2020; Ende et al., } \\
\text { 2015; Gambatese \& Hallowell, 2011; Hassan, 2021a; } \\
\text { Lim et al., 2010; Maier et al., 2020; Middleton, 2010; } \\
\text { Murphy et al., 2015; Ozorhon, 2013; Payán-Sánchez et }\end{array}$ \\
& $\begin{array}{l}\text { al., 2021; Repo \& Matschoss, 2019; Samson \& Gloet, } \\
\text { 2014; Szymczyk \& Kaminski, 2014; Shieh, 2011. }\end{array}$ \\
\hline 3 & $\begin{array}{l}\text { Adoption of innovative } \\
\text { ideas in sustainable } \\
\text { development projects can be } \\
\text { rejected or accepted } \\
\text { depending on the outcomes } \\
\text { of stage 1 and 2. }\end{array}$ & $\begin{array}{l}\text { Banyté \& Salickaitė, 2008; Bozkurt \& Kalkan, 2014; } \\
\text { Chatenier et al., 2010; Gambatese \& Hallowell, 2011; } \\
\text { Hassan, 2020; Ion \& Cristina, 2014; Lim et al., 2010; } \\
\text { Middleton, 2010; Payán-Sánchez et al., 2021; Samson } \\
\text { \& Gloet, 2014; Sheu \& Lee, 2011; Shieh, 2011; } \\
\text { Szymczyk \& Kaminski, 2014. }\end{array}$ \\
\hline
\end{tabular}

\section{An Integrative Model}

The integrative model of this study is shown in Figure 1. This model has been initiated considering the Diffusion of Innovation model established by Banyte and Salickaite (2008). This model has been integrated to cover wider aspects of the DOI theory and the three pillars of sustainability. The study proposed integrative three core states that are (1) creation of innovative ideas in sustainable development projects; (2) diffusion of innovative ideas in sustainable development projects; and (3) adoption of innovative ideas in sustainable development projects (Adams, 2016; Banytė \& Salickaite, 2008; Rogers 2003). Each one of these stages has factors that can lead to the success or failure of that particular stage. Failure factors would cause the diffusion of innovation to stop and ultimately fail (Alyoubi \& Yamin, 2021; Samson \& Gloet, 2014; Szymczyk \& Kaminski, 2014). Whereas, following consent, success factors would help in obtaining a smooth and continuous diffusion of innovation that leads to a successful implementation of innovation in SD projects (Adams, 2016; Alyoubi \& Yamin, 2021; Banytė \& Salickaitè, 2008; Rogers 2008; Samson \& Gloet, 2014; Szymczyk \& Kaminski, 2014). 


\subsection{Creation of Innovative Ideas in Sustainable Development Projects}

The creation of innovative ideas in SD projects is the first stage of the proposed integrative model. These phases include two possible outcomes (Alyoubi \& Yamin, 2021; Banyte \& Salickaite, 2008; Rogers 2008; Samson \& Gloet, 2014; Szymczyk \& Kaminski, 2014). The first option is the creation of inadequate innovation idea that is helpless for the SD projects. This stage is referred to as the "Creation Failure Factors". The second possibility is the creation of an adequate idea that enhances the outcome of SD projects. This phase is referred to as the "Creation Success Factors" (Banytė \& Salickaitè, 2008; Okour et al., 2021; Roger, 2003; Samson \& Gloet, 2014).

\subsubsection{Creation Failure Factors}

Banyte and Salickaite (2008) have stated that it is essential to be aware of the creation failure factors. These factors indicate the innovation was created in an unreliable way that could cause the DOI process to fail as well. In particular, the DOI creation failure factors in SD projects are low SD project performance; lack of resources; technical challenges; and lack of objectivity (Banytė \& Salickaitè, 2008; Ling et al., 2007; Ozorhon, 2013). First, a low SD project performance would make it harder to adopt and implement innovation effectively, as it could lack appropriate tools, skills, and technologies (Chatenier et al., 2010; Ling et al., 2007; Murphy et al., 2015). Second, lack of availability of skilled and experienced resources could negatively affect innovation (Chatenier et al., 2010; Gambatese \& Hallowell, 2011). Third, the continuous appearance of technical challenges throughout the phases of SD projects could be a barrier, especially, if these challenges couldn't be resolved in a short term (Hassan, 2021b; Repo \& Matschoss, 2019).

\subsubsection{Creation Success Factors}

On the other side, the DOI creation success factors can lead to successful adoption and implementation of innovation in SD projects. These factors are innovation exclusiveness; market orientation; preparatory work; well-defined conception; work performance quality; organizational structure; support of leadership; and creation process (Alyoubi \& Yamin, 2021; Banytė \& Salickaitè, 2008; Gayadeen \& Phillips, 2014; Samson \& Gloet, 2014).

\subsection{Diffusion of Innovative Ideas in Sustainable Development Projects}

Your Diffusion of innovative ideas in SD projects is the second phase of the proposed integrative model. It covers two alternatives. The first option is that the diffusion fails due to the "diffusion failure factors" (Banytė \& Salickaite, 2008; Chatenier et al., 2010; Gambatese \& Hallowell, 2011; Middleton, 2010; Murphy et al., 2015). While, the second option is that the innovation gets diffused adequately due to the successful adoption of the "Diffusion Success Factors" (Adams, 2016; Banytė \& Salickaitè, 2008; Bozkurt \& Kalkan, 2014; Ende et al., 2015; Lim et al., 2010; Samson \& Gloet, 2014; Szymczyk \& Kaminski, 2014; Shieh, 2011).

\subsubsection{Diffusion Failure Factors}

Diffusion failure factors are the factors that have the potential to stop the diffusion of 
innovation to occur is SD projects, causing failure of innovation (Banyte \& Salickaite, 2008; Chatenier et al., 2010; Gambatese \& Hallowell, 2011; Middleton, 2010; Murphy et al., 2015). These factors are competitors' actions; innovation cost; unattractive market; and adoption time (Banytė \& Salickaite, 2008 Gambatese \& Hallowell, 2011; Middleton, 2010; Murphy et al., 2015). In justification, competitors' actions towards innovation are critical, as some of the competitors could provide the same, or sometimes, better innovative solutions in their SD projects (Ende et al., 2015; Lim et al., 2010). This could negatively affect the diffusion of innovation, as the innovative solution would be considered as a common practice by competitors in the same market (Bozkurt \& Kalkan, 2014; Ende et al., 2015; Lim et al., 2010). Innovation cost is another failure factor. The reason is that most of the innovative products, services, and technologies are costly and require qualified and well-experienced professionals to adopt and implement them (Lim et al., 2010; Middleton, 2010). In other words, the required resources could be very expensive, which could be a burden for project professionals to attain or adopt (Bhardwaj, 2011; Lim et al., 2010; Ling et al., 2007; Middleton, 2010; Samson \& Gloet, 2014; Shieh, 2011). thus, this could result in the failure of the DOI in SD projects. Unattractive markets could also suppress the diffusion of innovation in SD projects, as it discourages project professionals to invest more budget, time, or effort to adopt and diffuse innovation in such projects (Ling et al., 2007; Hassan, 2021b; Murphy et al., 2015; Ozorhon, 2013). Yet, the wrong adoption time of innovation could negatively influence the diffusion of innovation in SD projects, leading it to fail (Hassan, 2020; Payán-Sánchez et al., 2021). The reason is that the adoption time of innovation could be associated with other issues such as the availability of budget, resources, products, or experienced project team members (Banyte \& Salickaite, 2008; Bhardwaj, Singh \& Kharayat, 2011; Samson \& Gloet, 2014).

\subsubsection{Diffusion Success Factors}

Researchers have questioned: "what are the success factors of adopted innovation during its further diffusion and adoption?" (Banyte \& Salickaite, 2008, P.50). This has increased the level of interest of other scholars to figure out what factors can lead to the success of DOI. Further, the diffusion success factors describe the attributes that lead to effective diffusion of innovation in sustainable development projects (Adams, 2016; Banytė \& Salickaitè, 2008; Bozkurt \& Kalkan, 2014; Ende et al., 2015; Lim et al., 2010; Samson \& Gloet, 2014; Szymczyk \& Kaminski, 2014; Shieh, 2011). These factors include adequate methodology; logical innovation adoption plan; and availability of resources (Banyte \& Salickaite, 2008; Cano \& Londoño-Pineda, 2020; Murphy et al., 2015). An adequate methodology is a key if accurate adoption and implementation of innovation, which in turn indicate a successful DOI (Maier et al., 2020; Repo \& Matschoss, 2019). A logical innovation adoption plan provides a robust strategy to diffuse innovation adequately throughout all stages of a project (Brem \& Puente-Díaz, 2020; Hassan, 2021a). In addition, the availability of resources (e.g. material, budget, manpower...etc.) is essential to diffuse innovation fruitfully throughout the SD project cycle (Cano \& Londoño-Pineda, 2020; Chatenier et al., 2010; Gambatese \& Hallowell, 2011).). The reason is that some of the resources required to deliver innovation have special expertise that could be hard to obtain (Gambatese \& Hallowell, 2011; Hassan, 2020; Repo \& 


\section{Macrothink

Matschoss, 2019).

\subsection{Adoption of Innovative ideas in Sustainable Development Projects}

The last stage of the DOI in SD projects is the adoption of an innovative idea in sustainable development projects (Banytė \& Salickaitè, 2008; Middleton, 2010; Sheu \& Lee, 2011). Hence, this stage has two options that are described as follows.

\subsubsection{Rejection of Innovative Ideas in Sustainable Development Projects}

The first scenario is the rejection of innovative ideas in SD projects, where the DOI stops or fails (Banytė \& Salickaitè, 2008; Hassan, 2021b; Repo \& Matschoss, 2019). In clarification, this could take place due to numerous reasons such as lack of commitment towards innovation (Shieh, 2011), unstable market (Bozkurt \& Kalkan, 2014; Szymczyk \& Kaminski, 2014), inexperienced employees (Gambatese \& Hallowell, 2011), and lack of training (Ling et al., 2007).

\subsubsection{Successful Adoption of Innovative Ideas in Sustainable Development Projects}

The second scenario is the successful adoption of innovative ideas in SD projects, where innovation would be diffused effectively and adequately in SD projects (Banytė \& Salickaitè, 2008; Hassan, 2020; Lim et al., 2010; Payán-Sánchez et al., 2021; Samson \& Gloet, 2014). As a result, the successful adoption has many advantages such as economic growth (Ion \& Cristina, 2014), competitive advantage (Lim et al., 2010), create a new market (Bozkurt \& Kalkan, 2014; Szymczyk \& Kaminski, 2014), adopt new technologies (Middleton, 2010), improve SD project quality (Szymczyk \& Kaminski, 2014), and establish an innovation culture that helps the SD project professionals move from traditional ways of performing projects to new reliable techniques (Shieh, 2011), unavailability of required material (Chatenier et al., 2010; Gambatese \& Hallowell, 2011), resistance to change (Chatenier et al., 2010; Gambatese \& Hallowell, 2011). 


\section{Macrothink Institute ${ }^{\mathrm{TM}}$}

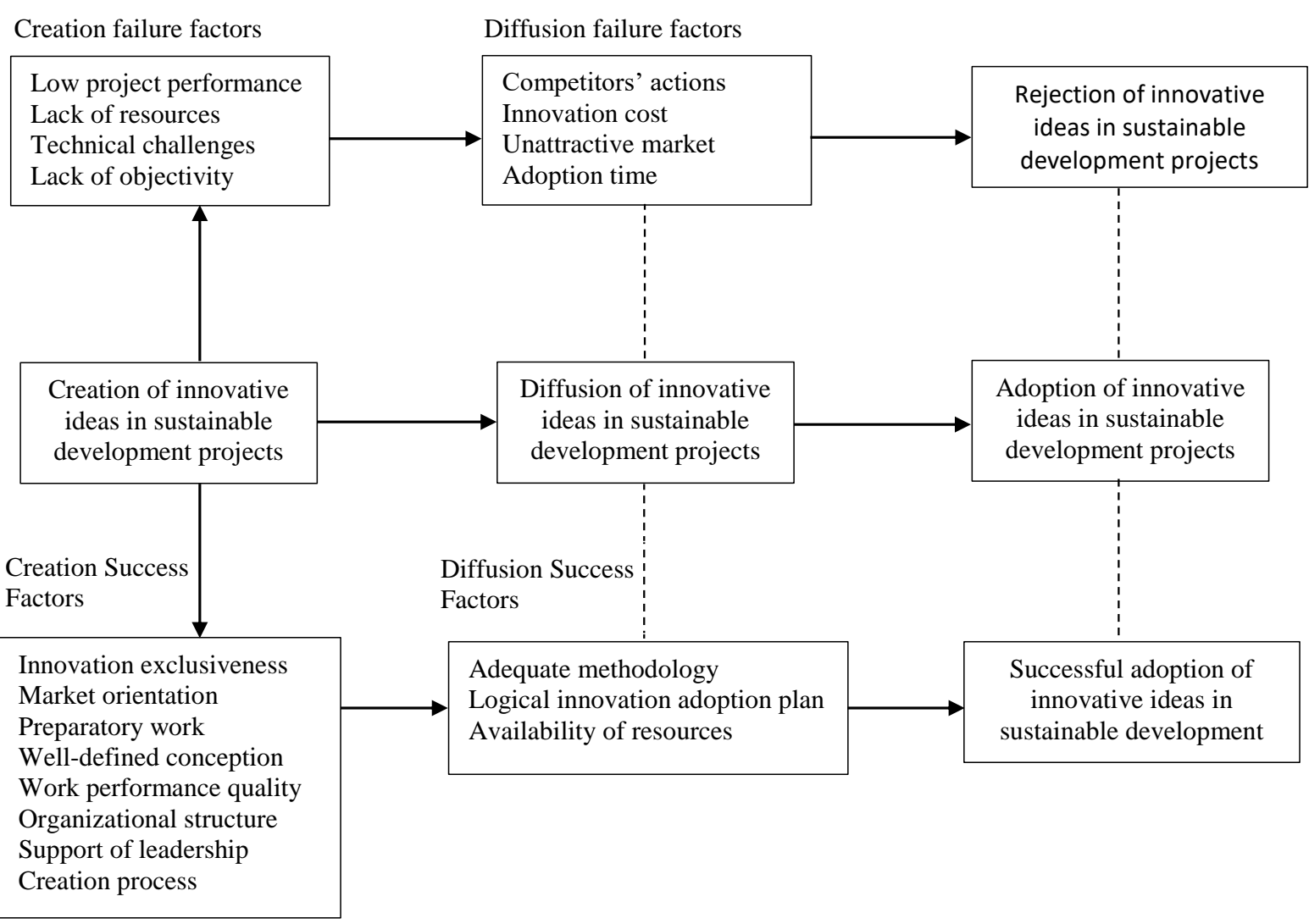

Figure 1. Conceptual Framework for Safety Management in Sustainable Construction Projects

Source: Developed by the Author

\section{Discussion}

Insights gained suggest that different factors drive the success or failure of the diffusion of innovation in sustainable development projects (Adams, 2016; Alyoubi \& Yamin, 2021; Banytė \& Salickaite, 2008; Rogers 2008; Samson \& Gloet, 2014; Szymczyk \& Kaminski, 2014). The study has emphasized that DOI in SD projects has three main stages that are (1) creation of innovative ideas in SD projects, (2) DOI ideas in SD projects, and (3) Adoption of innovative ideas in sustainable development projects (Adams, 2016; Banytė \& Salickaitè, 2008; Rogers 2003). The first stage has creation failure and success factors. The failure factors are that are low project performance, lack of resources, technical challenges, and lack of objectivity lead to failure of the DOI in SD projects (Banyte \& Salickaite, 2008; Bhardwaj et al., 2011; Lim et al., 2010; Ling et al., 2007; Samson \& Gloet, 2014). While, the success factors that are innovation exclusiveness, market orientation, preparatory work, well-defined conception, work performance quality, organizational structure, support of leadership, and creation process result in the success of DOI in SD projects (Adams, 2016; Banyte \& Salickaite, 2008; Bozkurt \& Kalkan, 2014; Ende et al., 2015; Lim et al., 2010; Samson \& Gloet, 2014; Szymczyk \& Kaminski, 2014; Shieh, 2011). However, the second stage includes diffusion failure and success factors. The diffusion failure factors that are competitors' actions, 
innovation cost, unattractive market, and adoption time can drive DOI to fail in SD projects (Banytė \& Salickaitè, 2008; Bozkurt \& Kalkan, 2014; Ende et al., 2015; Lim et al., 2010; Samson \& Gloet, 2014; Szymczyk \& Kaminski, 2014; Shieh, 2011). On the other side, the diffusion success factors that are adequate methodology, logical innovation adoption plan, and availability of resources can lead DOI to succeed in SD projects (Adams, 2016; Banyte \& Salickaite, 2008; Bozkurt \& Kalkan, 2014; Ende et al., 2015; Lim et al., 2010; Samson \& Gloet, 2014; Szymczyk \& Kaminski, 2014; Shieh, 2011). The third stage demonstrates two alternatives. One option is the rejection of innovative ideas in sustainable development projects, which indicates that innovation diffusion has failed or stopped in SD projects (Banyte \& Salickaite, 2008; Bhardwaj, Singh \& Kharayat, 2011; Payán-Sánchez et al., 2021; Samson \& Gloet, 2014). The other option is the successful adoption of innovative ideas in sustainable development, which implies that innovation has diffused effectively in SD projects (Bogers et al., 2020; Payán-Sánchez et al., 2021; Yun \& Liu, 2019). Whereas From an overarching perspective, the researcher concluded that the DOI in SD projects will succeed if the three core stages meet the success factors (Ciegis et al., 2011; Payán-Sánchez et al., 2021; Sachs, 2012; Samson \& Gloet, 2014). Yet, to improve and deliver better diffusion of innovation in SD projects, it is recommended to encourage better communication among team professionals; attain management support; overcome any challenges or obstacles that might arise due to human resources, financial and bureaucratic barriers (Bozkurt \& Kalkan, 2014). Thus, this study contributes to the body of knowledge by introducing an integrative model that summarizes the success and failure factors associated with the diffusion of innovation in sustainable development projects.

\section{Conclusion}

Although the current study determines the success and failure factors of DOI in SD projects, it is important to highlight limitations for future research. There are two major limitations of this study foremost this study is based on previous research about the topic. Thus, future research may conduct an empirical study to verify the findings of this paper. Secondly, the present study emphasizes the success and failure factors of DOI in SD projects. Hence, future research may generalize the findings of the study for a wider variety of projects. In other words, the DOI success and failure factors could be generalized to satisfy any type of project.

\section{Acknowledgments}

Countless thanks to Abu Dhabi University for providing valuable resources on its online library. The articles obtained ADU library and Google Scholars formed a solid basis for this research. Also, many thanks to the previous scholars who have scrutinized on the issues of diffusion of innovation and sustainable development projects.

\section{References}

Aczel, B., Szaszi, B., Sarafoglou, A., Kekecs, Z., Kucharský, Š., Benjamin, D., Chambers, C. D., Fisher, A., Gelman, A., Gernsbacher, M. A., \& Ioannidis, J. P. (2020). A consensus-based transparency checklist. Nature human behaviour, 4(1), 4-6.

https://doi.org/10.1038/s41562-019-0772-6 
Adams, R., Jeanrenaud, S., Bessant, J., Denyer, D., \& Overy, P. (2016). Sustainabilityoriented Innovation: A Systematic Review. International Journal of Management Reviews, 18(2), 180-205. https://doi.org/10.1111/ijmr.12068

Alyoubi, B., \& Yamin, M. (2021). Extending the Role of Diffusion of Innovation Theory (DOI) in Achieving the Strategic Goal of the Firm With the Moderating Effect of Cost Leadership. International Journal of System Dynamics Applications, 10(4), 1-22.

https://doi.org/10.4018/IJSDA.20211001.oa15

Banytė, J., \& Salickaite, R. (2008). Successful diffusion and adoption of innovation as a means to increase competitiveness of enterprises. Engineering Economics, 56(1), 48-65.

Bhardwaj, S., Singh, N., \& Kharayat, H. (2011). E- learning in higher education: need \& importance. International Journal of Education And Allied Sciences, 3(1), 17-122.

Bogers, M., Chesbrough, H., \& Strand, R. (2020). Sustainable open innovation to address a grand challenge. British Food Journal, 122(5), 1505-1517.

https://doi.org/10.1108/BFJ-07-2019-0534

Bozkurt, O. C., \& Kalkan, A. (2014). Business Strategies of SME s, Innovation Types and Factors Influencing Their Innovation: Burdur Model. Ege Akademik Bakis (Ege Academic Review), 14(2), 189-189. https://doi.org/10.21121/eab.2014218050

Brem, A., \& Puente-Díaz, R. (2020). Creativity, Innovation, Sustainability: A Conceptual Model for Future Research Efforts. Sustainability, 12(8), 3139.

https://doi.org/10.3390/su12083139

Cano, J. A., \& Londoño-Pineda, A. (2020). Scientific Literature Analysis on Sustainability with the Implication of Open Innovation. Journal of Open Innovation: Technology, Market, and Complexity, 6(4), 162. https://doi.org/10.3390/joitmc6040162

Chatenier, E., Verstegen, J. A. A. M., Biemans, H. J. A., Mulder, M., \& Omta, O. S. W. F. (2010). Identification of competencies for professionals in open innovation teams. $R \& D$ Management, 40(3), 271-280. https://doi.org/10.1111/j.1467-9310.2010.00590.x

Choi, P. (2020). A Need for Co-Evolution between Technological Innovations and Social Innovations. Journal of Open Innovation: Technology, Market, and Complexity, 6(3), 54. https://doi.org/10.3390/joitmc6030054

Christie, M., \& Jurado, R. (2009). Barriers to innovation in online pedagogy. European Journal of Engineering Education, 34(3), 273-279.

https://doi.org/10.1080/03043790903038841

Ciegis, R., Kliucininkas, L., \& Ramanauskiene, J. (2011). Assessment of state and tendencies of sustainable development in Lithuania. Management of Environmental Quality: An International Journal, 22(6), 757-768. https://doi.org/10.1108/14777831111170858

Dingfelder, H., \& Mandell, D. (2011). Bridging the Research-to-Practice Gap in Autism Intervention: An Application of Diffusion of Innovation Theory. Journal of Autism and 
Developmental Disorders, 41(5), 597-609. https://doi.org/10.1007/s10803-010-1081-0

Ende, J., Frederiksen, L., \& Prencipe, A. (2015). The Front End of Innovation: Organizing Search for Ideas. Journal of Product Innovation Management, 32(4), 482-487.

https://doi.org/10.1111/jpim.12213

Evanschitzky, H., Eisend, M., Calantone, R., \& Jiang, Y. (2012). Success Factors of Product Innovation: An Updated Meta-Analysis. Journal Of Product Innovation Management, 29, 21-37. https://doi.org/10.1111/j.1540-5885.2012.00964.x

Fukuda-Parr, S., \& Muchhala, B. (2020). The Southern origins of sustainable development goals: Ideas, actors, aspirations. World Development, 126, 104706.

https://doi.org/10.1016/j.worlddev.2019.104706

Gambatese, J. A., \& Hallowell, M. (2011). Enabling and measuring innovation in the construction industry. Construction Management and Economics, 29(6), 553-567.

https://doi.org/10.1080/01446193.2011.570357

Gayadeen, S., \& Phillips, S. (2014). The Innovation of Community Policing and the COPS Office: Does Diffusion of Innovation Theory Hold in a Manipulated Environment?. International Journal of Police Science \& Management, 16(3), 228-242.

https://doi.org/10.1350/ijps.2014.16.3.342

Granstrand, O., \& Holgerssonb, M. (2020). Innovation ecosystems: A conceptual review and a new definition. Technovation, 90-91. 102098.

https://doi.org/10.1016/j.technovation.2019.102098

Hassan, A. (2020). Managerial Competencies Required to Achieve Sustainable Development Projects: A Proposed Model for Managers. Environmental Management and Sustainable Development, 9(3), 68-86. https://doi.org/10.5296/emsd.v9i3.17603

Hassan, A. (2021a). Innovation Competencies and Sustainability: A Proposed Model for Project Team Members. International Journal of Regional Development, 8(2), 21-35. https://doi.org/10.5296/ijrd.v8i2.18841

Hassan, A. (2021b). The Antecedents and Challenges of Innovation in Sustainable Development Projects: Systematic Review. Environmental Management and Sustainable Development, 10(1), 76-91. https://doi.org/10.5296/emsd.v10i1.18329

Larsen, G. (2011). Understanding the early stages of the innovation diffusion process: awareness, influence and communication networks. Construction Management and Economics, 29(10), 987-1002. https://doi.org/10.1080/01446193.2011.619994

Lee, Y., Hsieh, Y., \& Hsu, C. (2011). Adding innovation diffusion theory to the technology acceptance model: supporting employees' intentions to use e-Learning systems. Journal Of Educational Technology \& Society, 14(4), 124-137. [Online] Available:

https://www.jstor.org/stable/jeductechsoci.14.4.124

Li, Y., Xiang, P., You, K., Guo, J., Liu, Z., \& Ren, H. (2021). Identifying the Key Risk 


\section{Macrothink}

Environmental Management and Sustainable Development

ISSN 2164-7682

2022, Vol. 11, No. 2

Factors of Mega Infrastructure Projects from an Extended Sustainable Development Perspective. International Journal of Environmental Research and Public Health, 18(14), 7515. https://doi.org/10.3390/ijerph18147515

Lim, J., Schultmann, F., \& Ofori, G. (2010). Tailoring Competitive Advantages Derived from Innovation to the Needs of Construction Firms. Journal of Construction Engineering and Management, 136(5), 568-580. https://doi.org/10.1061/(ASCE)CO.1943-7862.0000151

Ling, F. Y. Y., Hartmann, A., Kumaraswamy, M., \& Dulaimi, M. (2007). Influences on Innovation Benefits during Implementation: Client"s Perspective. Journal of Construction Engineering and Management, 133(4), 306-315.

https://doi.org/10.1061/(ASCE)0733-9364(2007)133:4(306)

Maier, D., Maier, A., Așchilean, I., Anastasiu, L., \& Gavriș, O. (2020). The Relationship between Innovation and Sustainability: A Bibliometric Review of the Literature. Sustainability, 12(10), 4083. https://doi.org/10.3390/su12104083

Mehmood, Y., Barbieri, N., \& Bonchi, F. (2015). Modeling adoptions and the stages of the diffusion of innovations. Knowledge and Information Systems, 48(1), 1-27.

https://doi.org/10.1007/s10115-015-0889-5

Middleton, D. (2010). Putting the Learning into E-learning. European Political Science, 9(1), 5-12. https://doi.org/10.1057/eps.2009.37

Murphy, M. E., Perera, S., \& Heaney, G. (2015). Innovation management model: a tool for sustained implementation of product innovation into construction projects. Construction Management and Economics, 33(3), 209-232.

https://doi.org/10.1080/01446193.2015.1031684

Okour, M., Chong, C., \& Abdel Fattah, F. (2021). Knowledge management systems usage: application of diffusion of innovation theory. Global Knowledge, Memory and Communication, 70(8/9), 756-776. https://doi.org/10.1108/GKMC-08-2020-0117

Ozorhon, B. (2013). Analysis of Construction Innovation Process at Project Level. Journal of Management in Engineering, 29(4), 455-463.

https://doi.org/10.1061/(ASCE)ME.1943-5479.0000157

Page, M., McKenzie, J., Bossuyt, P., Boutron, I., Hoffmann, T., \& Mulrow, C. et al. (2021). The PRISMA 2020 statement: an updated guideline for reporting systematic reviews. Systematic Reviews, 10(1). https://doi.org/10.1186/s13643-021-01626-4

Payán-Sánchez, B., Belmonte-Ureña, L., Plaza-Úbeda, J., Vazquez-Brust, D., Yakovleva, N., \& Pérez-Valls, M. (2021). Open Innovation for Sustainability or Not: Literature Reviews of Global Research Trends. Sustainability, 13(3), 1136. https://doi.org/10.3390/su13031136

Petticrew, M., \& Roberts, H. (2006). Systematic Reviews in the Social Sciences. A Practical Guide. Oxford: Willey-Blackwell. https://doi.org/10.1002/9780470754887

Remington-Doucette, S., \& Musgrove, S. (2015). Variation in sustainability competency 
development according to age, gender, and disciplinary affiliation: Implications for teaching practice and overall program structure. International Journal of Sustainability in Higher Education, 16(4), 537-575. https://doi.org/10.1108/IJSHE-01-2013-0005

Repo, P., \& Matschoss, K. (2019). Social Innovation for Sustainability Challenges. Sustainability, 12(1), 319. https://doi.org/10.3390/su12010319

Rogers, E. M. (2003). Diffusion of Innovations (5th Ed.). NY: The Free Press A Division of Simon and Schuster, Inc.

Sachs, J. (2012). From Millennium Development Goals to Sustainable Development Goals. The Lancet, 379(9832), 2206-2211. https://doi.org/10.1016/S0140-6736(12)60685-0

Samson, D., \& Gloet, M. (2014). Innovation capability in Australian manufacturing organisations: an exploratory study. International Journal of Production Research, 52(21), 6448-6466. https://doi.org/10.1080/00207543.2013.869368

Schleien, S., \& Miller, K. (2010). Diffusion of Innovation: A Roadmap for Inclusive Community Recreation Services. Research and Practice for Persons with Severe Disabilities, 35(3-4), 93-101. https://doi.org/10.2511/rpsd.35.3-4.93

Schwabe, O., Bilge, P., Hoessler, A., Tunc, T., Gaspar, D., ... Price, N. (2021). A Maturity Model for Rapid Diffusion of Innovation in High Value Manufacturing. Procedia CIRP, 96, 195-200. https://doi.org/10.1016/j.procir.2021.01.074

Secundo, G., Ndou, V., Vecchio, P., \& De Pascale, G. (2020). Sustainable development, intellectual capital and technology policies: A structured literature review and future research agenda. Technological Forecasting and Social Change, 153, 119917.

https://doi.org/10.1016/j.techfore.2020.119917

Sheu, D. D., \& Lee, H. (2011). A proposed process for systematic innovation. International Journal of Production Research, 49(3), 847-868.

https://doi.org/10.1080/00207540903280549

Shieh, C. (2011). Management innovation, corporation core competence and corporate culture: the impact of relatedness. Applied Economics Letters, 18(12), 1121-1124.

https://doi.org/10.1080/13504851.2010.526567

Szymczyk, M., \& Kamiński, B. (2014). Dynamics Of Innovation Diffusion With Two Step Decision Process. Foundations of Computing and Decision Sciences, 39(1), 39-53. https://doi.org/10.2478/fcds-2014-0004

Wiek, A., Withycombe, L., \& Redman, C. (2011). Key competencies in sustainability: a reference framework for academic program development. Sustainability Science, 6(2), 203-218. https://doi.org/10.1007/s11625-011-0132-6

Yun, J., \& Liu, Z. (2019). Micro- and Macro-Dynamics of Open Innovation with a Quadruple-Helix Model. Sustainability, 11(12), 3301. https://doi.org/10.3390/su11123301 


\section{Macrothink \\ Environmental Management and Sustainable Development \\ ISSN 2164-7682}

\section{Copyright Disclaimer}

Copyright for this article is retained by the author(s), with first publication rights granted to the journal.

This is an open-access article distributed under the terms and conditions of the Creative Commons Attribution license (http://creativecommons.org/licenses/by/4.0/). 